\title{
Caracterização de flogopita para processamento de filtros cerâmicos porosos pelo método da réplica
}

\section{(Characterization of phlogopite for processing porous ceramic filters using the replica method)}

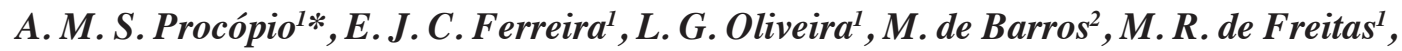 \\ M. C. da Silva ${ }^{3}$, F. Moura Filho ${ }^{1}$ \\ ${ }^{1}$ Universidade Federal de Itajubá, Laboratório Interdisciplinar de Materiais Avançados, \\ R. Irmã Ivone Drumond 200, 35903-087, Itabira, MG, Brasil \\ ${ }^{2}$ Universidade Federal de Ouro Preto, Pilar, MG, Brasil \\ ${ }^{3}$ Universidade Federal de Itajubá, Laboratório Interdisciplinar de Materiais Compósitos e Poliméricos, \\ Itabira, MG, Brasil
}

\begin{abstract}
Resumo
Descreve-se a caracterização da matéria-prima flogopita $\left[\mathrm{KMg}_{3}\left(\mathrm{AlSi}_{3} \mathrm{O}_{10}\right)(\mathrm{OH})_{2}\right]$ e o processo de fabricação de filtros cerâmicos porosos (FCPs) a partir desta, via método da réplica (esponja polimérica) de forma simples e eficaz. A flogopita foi caracterizada por difratometria de raios X (DRX), espectroscopia no infravermelho com transformada de Fourier por reflexão total atenuada, espectroscopia no UV-vis, termogravimetria, análise térmica diferencial e dilatometria, e os FCPs por microscopia eletrônica de varredura acoplada por espectroscopia por energia dispersiva e pelo método de imersão para determinação da porosidade aparente (PA), absorção de água (AA) e densidade aparente (DA). DRX indicou, além da fase flogopita, as fases caulinita, biotita e goetita para a amostra sem tratamento térmico. A energia de band gap de $3,10 \mathrm{eV}$ foi determinada por UV-vis. A partir das análises térmicas, encontrou-se a temperatura de queima do material entre 1000 e $1200{ }^{\circ} \mathrm{C}$. Determinaram-se PA na faixa de $92 \%$ a $95 \%$, AA de $84 \%$ a $89 \%$ e DA de 0,12 a $0,25 \mathrm{~g} . \mathrm{cm}^{-3}$. Os FCPs apresentaram altos teores dos elementos oxigênio, alumínio, silício, ferro e magnésio, além de estruturas celulares interconectadas com perfis circulares e distribuição de tamanho dos poros na faixa de 0,25 a 0,40 mm. Palavras-chave: caracterização, flogopita, filtros cerâmicos porosos, processamento, método da réplica.
\end{abstract}

\begin{abstract}
The characterization of the raw material phlogopite $\left[\mathrm{KMg}_{3}\left(\mathrm{AlSi}_{3} \mathrm{O}_{10}\right)(\mathrm{OH})_{2}\right]$ and the process of manufacturing porous ceramic filters $(P C F s)$ from it, using the polymeric sponge method in a simple and effective way, are described. Phlogopite was characterized by $X$-ray diffraction (XRD), attenuated total reflection Fourier-transform infrared spectroscopy, UV-vis spectroscopy, thermogravimetry, differential thermal analysis, and dilatometry, and PCFs by scanning electron microscopy coupled by energy dispersive spectroscopy and the immersion method to determine apparent porosity (PA), water absorption (AA), and bulk density (DA). XRD indicated, in addition to the phlogopite phase, the kaolinite, biotite, and goethite phases for the sample without heat-treatment. The band gap energy of $3.10 \mathrm{eV}$ was determined by $U V$-vis. From the thermal analysis, the firing temperature between 1000 and $1200{ }^{\circ} \mathrm{C}$ was

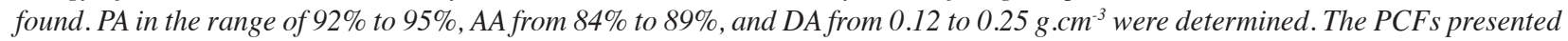
high contents of oxygen, aluminum, silicon, iron, and magnesium, besides regular cellular structures with interconnectivity, and pore size distribution in the range of 250 to $400 \mu \mathrm{m}$.
\end{abstract}

Keywords: characterization, porous ceramic filters, phlogopite, polymeric sponge method.

\section{INTRODUÇÃO}

Atualmente a poluição ambiental tem aumentado significativamente com o aumento da frota automotiva mundial e das indústrias, gerando grandes impactos aos ecossistemas, principalmente água, ar, fauna e flora, e eles pedem socorro. Com isso, torna-se necessário o

*alleymichael1987@gmail.com

Dhttps://orcid.org/0000-0001-8700-8782 desenvolvimento de novas técnicas, tecnologias, processos, métodos e materiais capazes de solucionar esses problemas de forma eficiente e sustentável. Nesse contexto, os materiais cerâmicos porosos (MCPs) têm recebido atenção significativa e vêm sendo estudados em várias aplicações tecnológicas, dos quais podem-se citar: suporte catalítico para tratamento de água e purificação de ar, em diversas reações químicas, adsorventes, sensores de gases, isolantes térmicos, membranas em altas temperaturas, implantes biomédicos, entre outros [1-4]. Os MCPs são materiais de baixa resistência mecânica devido à elevada porosidade 
constituídos de arranjos regulares e tridimensionais de células ocas, os quais podem apresentar poros fechados, abertos ou interconectados [4-6]. Esses materiais caracterizam-se por apresentar propriedades específicas de grande interesse, por exemplo, elevada área superficial, baixa densidade, baixa condutividade térmica, baixa constante dielétrica e alta permeabilidade [7-9], e em condições extremas podem ter resistência mecânica relativamente alta, alta resistência ao ataque químico, alta refratariedade e alta uniformidade estrutural $[10,11]$.

Diferentes técnicas de processamento e obtenção desses materiais são relatadas na literatura, das quais podem ser citadas: método da réplica ou esponja polimérica, formação direta de espumas cerâmicas e método de sacrifício pela queima de partículas orgânicas [12-16]. Neste trabalho foi utilizado o método da réplica (MR) para a obtenção de filtros cerâmicos porosos (FCPs) de flogopita. O MR é o mais utilizadodevidoà sua simplicidade e versatilidade na produção desses materiais, patenteado em 1963 por Schwartzwalder e Somers [21], que consiste na impregnação de uma esponja polimérica (molde), geralmente de poliuretano (PU) ou poliéster (PE), em uma suspensão cerâmica (SC), seguida de um tratamento térmico, que visa a queima e eliminação do material orgânico (esponja) e também a sinterização do corpo cerâmico, resultando em um material poroso de microestrutura similar à da esponja precursora [17-21]. Esse método torna-se bastante vantajoso em relação aos demais, pois é possível controlar a distribuição e tamanho dos poros, a espessura das hastes e a morfologia das células, a partir do controle e ajuste das variáveis de processamento das cerâmicas, como a viscosidade da SC e da escolha do molde polimérico [22].

A flogopita, matéria-prima utilizada neste estudo, é um mineral da família das micas, termo usado para referir-se a um agrupamento de minerais de silicatos formadores de rocha que ocorrem em uma ampla gama de condições de pressão e temperatura com a fórmula química geral $(\mathrm{K}, \mathrm{Na})$ $\mathrm{X}_{\mathrm{n}} \mathrm{AlSi}_{3} \mathrm{O}_{10}(\mathrm{OH}, \mathrm{F})_{2}$, na qual $\mathrm{X}$ pode ser $\mathrm{Al}^{3+}, \mathrm{Mn}^{2+}, \mathrm{Mn}^{3+}$, $\mathrm{Fe}^{2+}, \mathrm{Fe}^{3+}, \mathrm{Mg}^{2+}, \mathrm{Ti}^{2+}$ ou $\mathrm{Li}^{+}$, onde a estrutura cristalina consiste em camadas carregadas negativamente na razão 2:1 que são compensadas por cátions intercalares $\mathrm{K}^{+}, \mathrm{Na}^{+}$, $\mathrm{Ca}^{2+}$, entre outros. Na estrutura unitária, essas camadas são apresentadas em forma de folhas, sendo duas tetraédricas e uma octaédrica; a flogopita é classificada como mica de magnésio trioctaédrica com fórmula química ideal $\mathrm{KMg}_{3}\left(\mathrm{AlSi}_{3} \mathrm{O}_{10}\right)(\mathrm{OH})_{2}$ rica em cátions de magnésio, potássio, silício e alumínio, na qual cada íon hidroxila localiza-se acima de três íons $\mathrm{Mg}^{2+}$ e sob um íon $\mathrm{K}^{+}$; entretanto, na natureza o magnésio e o grupo hidroxila são usualmente substituídos por ferro ferroso e flúor, respectivamente [2327]. De modo geral, a flogopita apresenta uma coloração amarelada, esverdeada ou castanha avermelhada e pertence ao grupo dos filossilicatos, que são importantes na crosta terrestre, pois minerais de fontes de silicatos apresentam o maior depósito de magnésio e cálcio na superfície da Terra [28]. As micas são largamente utilizadas como isolantes (térmicos, elétricos ou acústicos) e a flogopita, sendo da mesma família, tem grande potencial tecnológico. $\mathrm{Na}$ literatura, alguns estudos são relatados, por exemplo, Xu et al. [29] citam alguns trabalhos da literatura que introduzem partículas de mica em matrizes poliméricas de insonorização para controles de ruídos e descobriram que um aumento na rigidez tem um papel importante nas propriedades de isolamento acústico; já Yang et al. [30] estudaram um modelo simplista de células unitárias de absorção sonora para espumas altamente porosas, com células totalmente abertas ou semiabertas. Além disso, Lapcík et al. [31] testaram a capacidade de absorção sonora de pós de mica (muscovita e flogopita) em compósitos poliméricos. Já Yuan et al. [32] sintetizaram compostos de mica-titânia revestidos com $\mathrm{BiVO}_{3}$ para avaliar o desempenho de isolamento térmico em materiais para telhados e $\mathrm{Lu}$ et al. [33] estudaram a viabilidade da utilização da mica muscovita como substrato dielétrico para filmes poliméricos conjugados aplicados em transistores orgânicos de efeito de campo, sendo a mica muscovita o material mais utilizado para isolamento elétrico devido à alta rigidez dielétrica, alta constante dielétrica e baixa perda dielétrica.

Neste contexto, este trabalho tem como objetivo caracterizar a flogopita, um mineral da família das micas e subproduto de filossilicatos de processos industriais, por análise de difração de raios $\mathrm{X}$, espectroscopia no infravermelho, ultravioleta e visível, termogravimetria, análise térmica diferencial e dilatometria, para o processamento de filtros cerâmicos porosos (FCPs) via método da réplica (MR), um método simples e bastante prático, determinando a porosidade aparente, absorção de água e densidade aparente pelo método de imersão baseado no princípio de Arquimedes, para viabilizar seu aproveitamento em futuras aplicações tecnológicas.

\section{EXPERIMENTAL}

Processamento dos filtros cerâmicos porosos (FCPs): a matéria-prima utilizada foi uma flogopita processada, fornecida pela Solocores Pigmentos (Ouro Preto, Brasil), um subproduto do filossilicato obtido no município de Itabira (Minas Gerais, Brasil). Para a conformação de FCPs de flogopita foi utilizado o método da réplica ou método da esponja polimérica (MEP), para obtenção de uma estrutura interligada e similar à matriz polimérica. Primeiramente preparou-se uma barbotina de suspensão cerâmica (SC) de flogopita, na qual foram adicionados $100 \mathrm{~g}$ de flogopita, 140 $\mathrm{mL}$ de água destilada, $2 \%$ de defloculante silicato de sódio $\left(\mathrm{Na}_{2} \mathrm{SiO}_{3}\right.$, Dinâmica, $18 \% \mathrm{Na}_{2} \mathrm{O}$ e $\left.63 \% \mathrm{SiO}_{2}\right)$ e $0,5 \mathrm{~mL}$ de hidróxido de amônio $\left(\mathrm{NH}_{4} \mathrm{OH}\right.$, Alphatec, pureza $\left.30 \%\right)$. Em seguida, os componentes (flogopita, água, defloculante e $\mathrm{NH}_{4} \mathrm{OH}$ ) foram misturados em moinho de bolas (MA500/ CF, Marconi) com velocidade constante de $600 \mathrm{rpm}$ por $24 \mathrm{~h}$. $\mathrm{O}$ processo de impregnação foi realizado de forma manual, onde as EPs (esponjas poliméricas) de PU (poliuretano) comerciais com texturas e porosidades diferentes das marcas Limpuss, Scotch Brite, Bom Bril e Assolan foram utilizadas como moldes para a produção dos FCPs por imersão na 
SC. Este processo foi repetido várias vezes até as esponjas estarem completamente encharcadas e, posteriormente, os materiais foram comprimidos para a retirada do excesso de SC. As esponjas impregnadas foram secas à temperatura ambiente por $24 \mathrm{~h}$ para permitir a evaporação da água e, em seguida, levadas ao forno de alta temperatura (3P-5, EDG) para pirólise do $\mathrm{PU}$ e queima dos materiais com a seguinte rampa de aquecimento: $400{ }^{\circ} \mathrm{C}$ por $60 \mathrm{~min}, 900{ }^{\circ} \mathrm{C}$ por 60 min e $1100^{\circ} \mathrm{C}$ por $120 \mathrm{~min}$, com taxas de aquecimento de 1 , 2 e $5{ }^{\circ} \mathrm{C} \cdot \mathrm{min}^{-1}$, respectivamente.

Caracterização: diferentes técnicas foram utilizadas, entretanto, inicialmente a matéria-prima foi macerada e/ou desaglomerada em um almofariz de ágata e peneirada em malha de abertura 100 mesh $(150 \mu \mathrm{m})$. Posteriormente, o material foi seco em uma estufa (SP 400, SP-Labor) a 110 ${ }^{\circ} \mathrm{C}$ por $24 \mathrm{~h}$. Difratometria de raios $X(D R X)$ : a análise da cristalinidade e identificação das fases do material foi verificada a partir da técnica de DRX.A amostra foi espalhada homogeneamente sobre uma lâmina de vidro e o equipamento utilizado foi um difratômetro (SmartLab, Rigaku) com tubo de cobre (CuKa, $\lambda=1,5406 \AA$ ), tensão de aceleração de $30 \mathrm{kV}$ e corrente de $30 \mathrm{~mA}$; a medida foi realizada no intervalo de $2 \theta$ de $10^{\circ}$ a $70^{\circ}$, passo de $0,05^{\circ}$ e velocidade de $0,75 \mathrm{s.passo}^{-1}$. Espectroscopia no infravermelho com transformada de Fourier (FTIR) por reflexão total atenuada $(A T R)$ : a análise para identificação de unidades estruturais com base nas frequências vibracionais das moléculas foi verificada por ATR-FTIR. A análise foi conduzida em um espectrômetro (Vertex 70, Bruker) com resolução de 0,5 $\mathrm{cm}^{-1}$ e 64 varreduras em uma região espectral de 200 a 4000 $\mathrm{cm}^{-1}$. Espectroscopia no ultravioleta e visível (UV-vis): a análise para identificação e compreensão das estruturas das bandas eletrônicas foi verificada por espectroscopia óptica na região do UV-vis. A análise foi conduzida em um espectrômetro (UV-Vis 2600, Shimadzu) submetido a uma velocidade de varredura média em uma região espectral de 185 a $1400 \mathrm{~nm}$ para os cálculos da energia do band gap $\left(\mathrm{E}_{\text {gap }}\right)$ do material. Termogravimetria $(T G)$ e análise térmica diferencial (DTA): a análise para avaliação e identificação dos processos de decomposição e comportamento térmico do material foi verificada por TG e a análise para a avaliação e identificação dos efeitos de calor associados com alterações físicas ou químicas em função da temperatura com um material de referência termicamente inerte foi verifica por DTA. As análises foram registradas simultaneamente em uma termobalança (STA 8000, PerkinElmer) submetida a aquecimento de $5{ }^{\circ} \mathrm{C} \cdot \mathrm{min}^{-1}$ sob fluxo de gás nitrogênio de $20 \mathrm{~cm}^{3} \cdot \mathrm{min}^{-1}$ de 35 a $1450{ }^{\circ} \mathrm{C}$ em um cadinho de alumina. Dilatometria (DIL): a análise para avaliação da retração linear $\left(\Delta \mathrm{L} / \mathrm{L}_{0}\right)$ do corpo de prova, quando submetido a um programa controlado de aquecimento e determinação da temperatura de queima, foi verificada por dilatometria. A amostra passou por um processo de conformação em um pastilhador com formato cilíndrico e posteriormente compactada por um sistema isostático sob $200 \mathrm{MPa}$ por $1 \mathrm{~min}$ em uma prensa hidráulica, obtendo-se uma pastilha com dimensões de 3,71 $\mathrm{mm}$ de diâmetro e 4,18 $\mathrm{mm}$ de comprimento. Em seguida, a análise foi conduzida em um dilatômetro (DIL 402C, Netzch) com aquecimento de $5{ }^{\circ} \mathrm{C} \cdot \mathrm{min}^{-1}$ de 20 a $1500{ }^{\circ} \mathrm{C}$. Porosidade aparente (PA), absorção de água $(A A)$ e densidade aparente (DA) pelo método de imersão: os ensaios dos FCPs queimados foram realizados pelo método de imersão baseado no princípio de Arquimedes para determinar a porosidade aparente (PA), absorção de água (AA) e densidade aparente (DA). Incialmente foi medida a massa seca $\left(\mathrm{m}_{\mathrm{s}}\right)$ dos FCPs queimados e, em seguida, foram imersos em água destilada à temperatura ambiente e deixados por $24 \mathrm{~h}$. Posteriormente foram realizadas medidas da massa úmida $\left(\mathrm{m}_{\mathrm{u}}\right)$ e massa submersa $\left(\mathrm{m}_{\text {sub }}\right)$ dos mesmos em uma balança analítica. Essas propriedades foram determinadas pelas seguintes equações [34]:

$$
\begin{aligned}
& \operatorname{PA}(\%)=\frac{\mathrm{m}_{\mathrm{u}}-\mathrm{m}_{\mathrm{s}}}{\mathrm{m}_{\mathrm{u}}-\mathrm{m}_{\text {sub }}} \cdot 100 \\
& \mathrm{AA}(\%)=\frac{\mathrm{m}_{\mathrm{u}}-\mathrm{m}_{\mathrm{s}}}{\mathrm{m}_{\mathrm{u}}} \cdot 100 \\
& \mathrm{DA}=\frac{\mathrm{m}_{\mathrm{s}}}{\mathrm{m}_{\mathrm{u}}-\mathrm{m}_{\text {sub }}} \cdot \rho_{\mathrm{i}}
\end{aligned}
$$

em que $\mathrm{Q}_{\mathrm{i}}$ é a densidade $\left(0,9968{\mathrm{~g} . \mathrm{cm}^{-3}}^{-3}\right)$ do líquido (água) corrigida para a temperatura $\left(26^{\circ} \mathrm{C}\right)$ no momento dos ensaios. Microscopia eletrônica de varredura (MEV) acoplada por espectroscopia por energia dispersiva (EDS): as análises por MEV e EDS foram utilizadas para avaliar, detectar e caracterizar a estrutura morfológica do corpo de prova de flogopita. As amostras foram fixadas em suporte metálico de alumínio com fita dupla face e analisadas em um microscópio eletrônico de varredura de alta resolução (VEGA 3, Tescan) com imageamento por elétrons retroespalhados (BSE) e equipado com um detector de fluorescência de raios X (XFlash 410-M, Bruker) para a geração do espectro de EDS, que forneceu uma análise química semiquantitativa acerca do material analisado.

\section{RESULTADOS E DISCUSSÃO}

A Fig. 1a apresenta o padrão de difração de raios $\mathrm{X}$ para a amostra de flogopita segundo indexação do arquivo cristalográfico JCPDS (Joint Committe on Powder Diffraction Standards) 10-492 para a estrutura cristalina do tipo monoclínica. O difratograma apresentou as fases cristalinas da matéria-prima flogopita, o que representa a sua composição mineralógica, além da existência e identificação de outras fases cristalinas como a caulinita $\left[\mathrm{Al}_{2} \mathrm{Si}_{2} \mathrm{O}_{5}(\mathrm{OH})_{4}\right]$, biotita $\left(\mathrm{KMg}_{3} \mathrm{AlSi}_{3} \mathrm{O}_{10} \mathrm{OHF}\right)$ e goetita $(\mathrm{FeO} . \mathrm{OH})$. Ressaltase que a amostra de flogopita não foi submetida a nenhum tratamento térmico prévio, demonstrando seu grau de cristalinidade perante o seu estado natural. Sreenivasan et al. [25] relatam que a flogopita é estável termicamente para uma calcinação entre 300 e $900{ }^{\circ} \mathrm{C}$ e em temperaturas superiores se decompõe gerando outras fases, por exemplo, a magnetita, leucita, dentre outras. Além disso, amostras de flogopita com presença de ferro apresentam a fase goetita. 

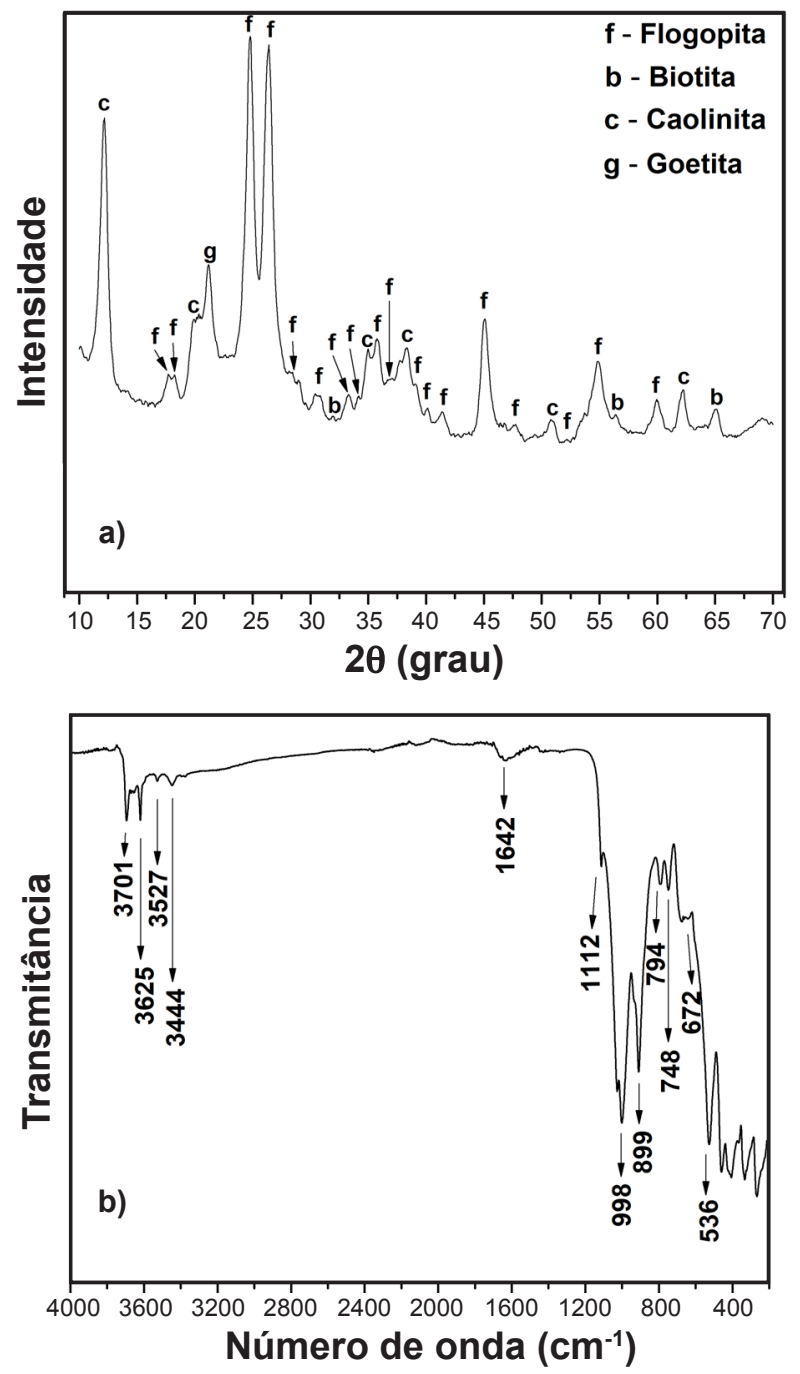

Figura 1: Difratograma de raios X (a) e espectro de ATR-FTIR (b) da amostra de flogopita sem tratamento térmico.

[Figure 1: X-ray diffractogram (a) and ATR-FTIR spectrum (b) of the phlogopite sample without heat-treatment.]

A natureza química da amostra de flogopita foi comprovada pelo espectro de ATR-FTIR (Fig. 1b). As bandas de estiramento observadas em 3701 e $3625 \mathrm{~cm}^{-1}$ foram atribuídas às hidroxilas $\left(\mathrm{OH}^{-}\right)$ligadas ao grupo $\mathrm{Mg}_{3}(\mathrm{OH})$, ou seja, aos 3 íons $\mathrm{Mg}^{2+}$, que são habitualmente descritas para micas/filossilicatos magnesianos [35-37], como observado no difratograma para as fases flogopita e biotita, sendo que ambas contêm hidroxilas e magnésio. Já as bandas de estiramentos em 3527 e $3444 \mathrm{~cm}^{-1}$ foram relacionadas às vibrações de alongamentos de $\mathrm{OH}^{-}$da água, a qual foi confirmada por uma banda característica em 1642 $\mathrm{cm}^{-1}$, conhecida como vibração de curvatura [37, 38]. Isso confirmou o resultado da análise de DRX, pois as fases flogopita, biotita, caulinita e goetita apresentam hidroxilas em suas estruturas cristalinas. De acordo com [35], algumas bandas típicas da flogopita incluem a vibração de $-\mathrm{OH}$ em $600 \mathrm{~cm}^{-1}$, vibrações no plano associadas às ligações Al-O-Si em 660 e $730 \mathrm{~cm}^{-1}$, uma vibração perpendicular da camada tetraédrica em $690 \mathrm{~cm}^{-1}$, uma vibração referente à ligação Al-O do tetraedro $\mathrm{AlO}_{4}$ em $820 \mathrm{~cm}^{-1}$ e um sinal intenso do estiramento de $\mathrm{Si}-\mathrm{O}$ em $986 \mathrm{~cm}^{-1}$, na qual foram também identificadas as bandas em 672, 748, 794, 899 e $998 \mathrm{~cm}^{-1}$ [35, 38].

A Fig. 2 apresenta o espectro de UV-vis para a amostra de flogopita com seu respectivo valor de band gap. $\mathrm{E}_{\text {gap }}$ foi determinado a partir do modelo de Kubelka-Munk, baseado em medidas de refletância difusa [39, 40], onde o band gap foi inferido a partir do ajuste dos dados de absorção à equação de transição eletrônica permitida direta, extrapolando a porção linear da curva para absorção igual a zero. A partir do valor da energia de band gap obtido $(3,10 \mathrm{eV})$, de acordo com [41], materiais à base de flogopita podem ser classificados como semicondutores.

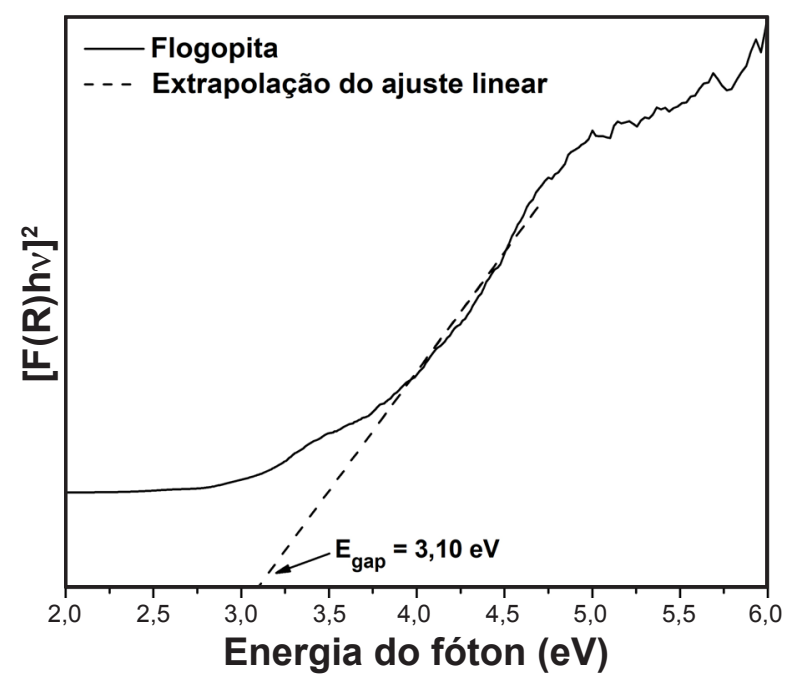

Figura 2: Espectro de UV-vis da amostra de flogopita sem tratamento térmico para determinação da energia de band gap.

[Figure 2: UV-vis spectrum of the phlogopite sample without heat treatment for determination of band gap energy.]

Em relação à análise térmica do material para investigar, determinar e obter a temperatura de calcinação e os eventos de perda de massa, a Fig. 3a apresenta as curvas de TG/DTA para a amostra de flogopita sem tratamento térmico até 1450 ${ }^{\circ} \mathrm{C}$. A partir da curva de TG foi possível evidenciar 4 eventos de perda de massa. A $1^{\mathrm{a}}$ e $2^{\mathrm{a}}$ perdas de massa ocorreram na faixa entre 50 e $300{ }^{\circ} \mathrm{C}$, que podem ser atribuídas às moléculas de água fracamente ligadas por hidratação e de gases adsorvidos na superfície do material, correspondente ao pico exotérmico em $350^{\circ} \mathrm{C}$ na curva de DTA. O $3^{\circ}$ evento de perda de massa ocorreu na faixa entre 300 e $600{ }^{\circ} \mathrm{C}$, que pode ser atribuído às moléculas de água fortemente ligadas por hidroxilação, em correspondência ao pico exotérmico em $480{ }^{\circ} \mathrm{C}$ da curva de DTA. O $4^{\circ}$ e último evento de perda de massa ocorreu entre 1280 e $1400{ }^{\circ} \mathrm{C}$, que pode ser associado ao pico exotérmico em $1300^{\circ} \mathrm{C}$, atribuído à mudança de fase e/ou fusão do material, confirmada pela Fig. 3b.

A Fig. 3b apresenta a curva dilatométrica obtida de um compacto a verde de flogopita sem tratamento térmico, para indicar a temperatura adequada para a queima dos filtros 

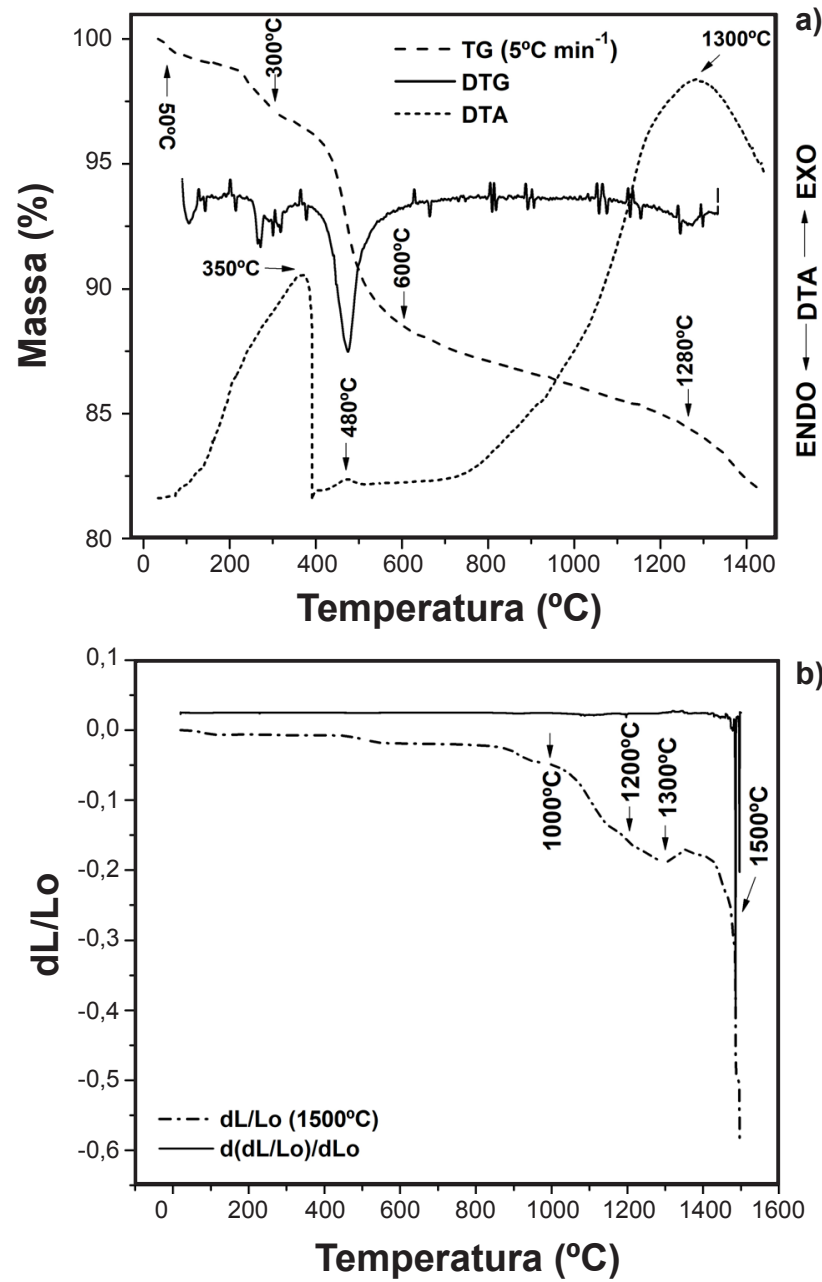

Figura 3: Curvas de TG, DTG e DTA (a) e DIL (b) da amostra de flogopita sem tratamento térmico.

[Figure 3: TG, DTG, and DTA (a) and dilatometry (b) curves of the phlogopite sample without heat treatment.]

cerâmicos porosos (FCPs), indo até a fusão. Observou-se que o corpo cilíndrico não apresentou retração linear significativa até $900^{\circ} \mathrm{C}$ e acima de $1000^{\circ} \mathrm{C}$ foi possível observar o início da retração linear do material, correspondente ao início da temperatura de queima. Próximo a $1200{ }^{\circ} \mathrm{C}$ foi observado o final da retração linear, equivalente à temperatura final de queima, entretanto a partir de $1300^{\circ} \mathrm{C}$ ocorreu uma expansão do material, que pode ser atribuída à formação de uma fase líquida e posteriormente uma retração linear abrupta até $1500{ }^{\circ} \mathrm{C}$, relacionada com a fusão total do material.

Com o intuito de verificar a morfologia dos FCPs, utilizouse o MEV.As micrografias porBSE(Fig.4) revelaram algumas diferenças texturais entre os materiais obtidos, dentre elas: grau de porosidade, interconectividade e tamanho dos poros. Os FCPs apresentaram estruturas celulares semelhantes, poros interconectados de configurações geométricas quase esféricas e/ou relativamente hexagonais, entretanto, também apresentaram poros fechados ou obstruídos por uma fina camada do material, sendo atribuída à viscosidade elevada da suspensão cerâmica, propícia para o entupimento dos poros, além de trincas e fraturas que podem ocorrer durante a pirólise ou decomposição do molde polimérico de PU,

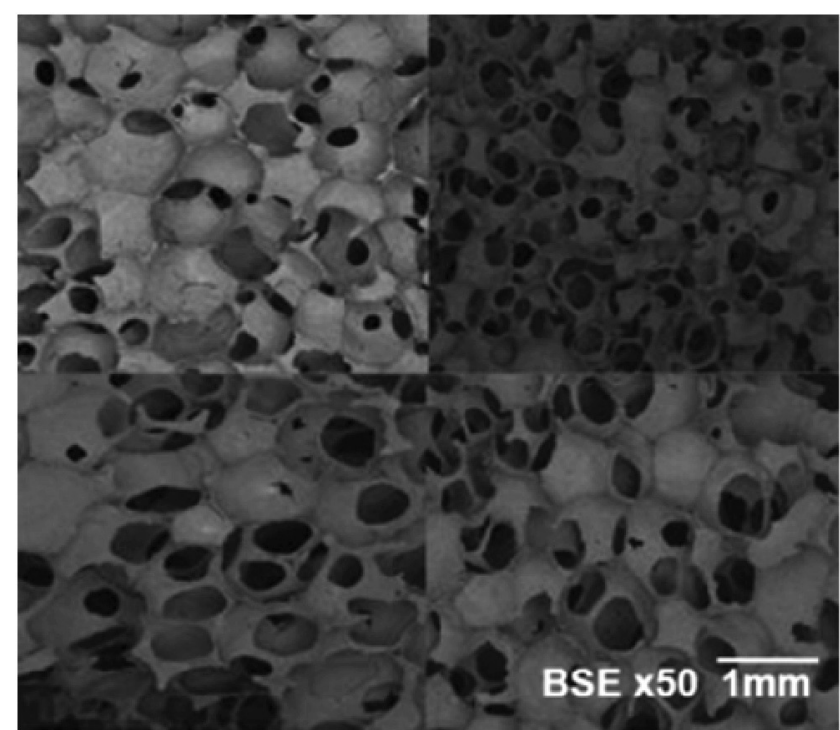

Figura 4: Micrografias de MEV-BSE dos FCPs de flogopita. [Figure 4: SEM-BSE micrographs of phlogopite-derived porous ceramic filters (PCFs).]

previstos quando se utiliza o método da réplica (MR) [4, 16, 19]. Na literatura são relatados vários trabalhos que utilizam o método da réplica na produção de FCPs, por isso a sua utilização nesse estudo. Por exemplo, Choudhary et al. [1] relatam que o método de replicação é um dos mais simples e versáteis, pois apresenta grau de porosidade na faixa de $40 \%$ a $95 \%$ e estrutura bastante reticulada, entretanto, as cerâmicas reticuladas apresentam hastes ocas e trincadas após a pirólise e baixa resistência mecânica, que está diretamente relacionada com a porosidade, tamanho dos poros, composição do material e densidade das hastes. Já Soraru et al. [12] obtiveram uma cerâmica porosa de SiOC pelo método da réplica a partir de uma solução de polímero pré-cerâmico com poros interconectados de configuração quase hexagonal, que apresentaram hastes densas e sem trincas.

A análise elementar semiquantitativa dos FCPs de flogopita é apresentada na Tabela I. A partir do espectro de EDS, foi possível identificar os elementos presentes. Oxigênio, titânio, potássio, ferro, magnésio, alumínio e silício foram encontrados na composição química do material, que corroborou as bandas de estiramento $\mathrm{Mg}^{2+}$ $\mathrm{OH}^{-}$e vibrações associadas às ligações Al-O-Si, Al-O e Si-O apresentadas no espectro ATR-FTIR da flogopita. Conforme a literatura [24, 25, 27], a flogopita de fórmula química geral $(\mathrm{K}, \mathrm{Na}) \mathrm{X}_{\mathrm{n}} \mathrm{AlSi}_{3} \mathrm{O}_{10}(\mathrm{OH}, \mathrm{F})_{2}$ apresenta os elementos alumínio, ferro, magnésio e titânio no sítio X. Os resultados da Tabela I sugerem que o material estudado seja mica/filossilicato de magnésio com altos teores de cátions de magnésio, potássio, silício e alumínio [25, 28, 42].

A partir do método de imersão em água baseado no princípio de Arquimedes, foi possível determinar alguns parâmetros, como a porosidade aparente, absorção de água e densidade aparente dos FCPs. De acordo com a Tabela II, os materiais apresentaram porosidade aparente na faixa de $92 \%$ a 95\%, capacidade de absorção de água na faixa de $84 \%$ a 
Tabela I - Análise elementar (composição química) obtida por EDS dos FCPs.

[Table I - Elemental analysis (chemical composition) obtained by EDS of PCFs.]

\begin{tabular}{cc}
\hline Elemento & Teor $(\%)$ \\
\hline Oxigênio $(\mathrm{O})$ & 65,02 \\
Titânio $(\mathrm{Ti})$ & 0,30 \\
Potássio $(\mathrm{K})$ & 0,90 \\
Ferro $(\mathrm{Fe})$ & 6,55 \\
Magnésio $(\mathrm{Mg})$ & 1,47 \\
Alumínio $(\mathrm{Al})$ & 14,00 \\
Silício $(\mathrm{Si})$ & 11,76 \\
\hline
\end{tabular}

Tabela II - Resultados de porosidade aparente (PA), absorção de água (AA) e densidade aparente (DA) dos FCPs.

[Table II - Results of apparent porosity (PA), water absorption (AA), and bulk density (DA) for PCFs.]

\begin{tabular}{cccc}
\hline Amostra & PA $(\%)$ & AA $(\%)$ & DA $\left(\mathrm{g} \cdot \mathrm{cm}^{-3}\right)$ \\
\hline 1 & 92,88 & 84,33 & 0,2508 \\
2 & 94,35 & 87,99 & 0,1793 \\
3 & 93,43 & 85,19 & 0,2127 \\
4 & 95,64 & 89,32 & 0,1295 \\
\hline
\end{tabular}

$89 \%$ e densidade aparente na faixa de 0,12 a $0,25 \mathrm{~g} . \mathrm{cm}^{-3}$. Observou-se que o aumento da porosidade foi diretamente relacionado com o aumento da capacidade de absorção de água dos FCPs, e a densidade aparente dos materiais foi maior para menor porosidade. Assim, a flogopita, por ser da família das micas e pelas suas características após processamento como FCP pelo método da réplica, pode ser de grande interesse tecnológico no processo de fabricação de isolantes térmicos, acústicos e elétricos, semicondutores, purificadores de ar ou água, catalisadores ou fotocatalisadores e sensores gasosos, entre outros.

\section{CONCLUSÕES}

A matéria-prima flogopita, um mineral filossilicato rico em magnésio, foi caraterizada por DRX, ATR-FTIR, UVvis, TG, DTA e DIL, e utilizada no processamento de filtros cerâmicos porosos (FCPs) empregando o método da réplica de forma satisfatória. A partir da análise de DRX foi possível identificar a fase flogopita, além das fases cristalinas caulinita $\left[\mathrm{Al}_{2} \mathrm{Si}_{2} \mathrm{O}_{5}(\mathrm{OH})_{4}\right]$, biotita $\left(\mathrm{KMg}_{3} \mathrm{AlSi}_{3} \mathrm{O}_{10} \mathrm{OHF}\right)$ e goetita $(\mathrm{FeO} . \mathrm{OH})$. A energia de band gap encontrada pelo modelo de Kubelka-Mulk para uma transição eletrônica permitida direta foi de 3,10 eV. Os FCPs apresentaram interconectividade dos poros e uma distribuição de tamanho dos poros na faixa 0,25 a $0,40 \mathrm{~mm}$, que foi diretamente relacionada com a densidade de poros das esponjas de PU selecionadas, além de apresentar porosidade aparente na faixa de $92 \%$ a $95 \%$, absorção de água de $84 \%$ a $89 \%$ e densidade aparente entre 0,12 e $0,25 \mathrm{~g} \cdot \mathrm{cm}^{-3}$. A temperatura de queima dos FCPs foi de $1100{ }^{\circ} \mathrm{C}$, conforme a faixa de temperatura de queima obtida da análise dilatométrica.

\section{AGRADECIMENTOS}

Os autores gostariam de agradecer à Coordenação de Aperfeiçoamento de Pessoal do Nível Superior (CAPES) pela bolsa de estudo, à Fundação de Amparo à Pesquisa do Estado de Minas Gerais (FAPEMIG), à Rede Mineira de Química de Minas Gerais (RQ-MG) e ao Programa de PósGraduação Multicêntrico em Química (PPGMQ).

\section{REFERÊNCIAS}

[1] A. Choudhary, S.K. Pratihar, S.K. Behera, Ceram. Int. 45 (2019) 8063.

[2] G.S. Falk, A.L. Rodriguez, W. Acchar, E.L. Foletto, Cerâmica 60, 353 (2014) 102.

[3] A.G.S. Galdino, C.A.C. Zavaglia, Cerâmica 58, 347 (2012) 388 .

[4] K. Donadel, J.M. Gomes, C.R. Rambo, D. Hortza, A.P.N. Oliveira, Exacta 6 (2008) 41.

[5] L. Borchardt, C. Hoffmann, M. Oschatz, L. Mammitzsch, U. Petasch, M. Herrmann, S. Kaskel, Chem. Soc. Rev. 41 (2012) 5053.

[6] E. de Sousa, F.S. Ortega, V.C. Pandolfelli, Cerâmica 55, 334 (2009) 151.

[7] J.-H. Ha, S. Lee, J.R. Choi, J. Lee, I.-H. Song, S.J. Lee, J. Choi, Ceram. Int. 43 (2017) 16924.

[8] Y. Han, H. Kim, M. Tong, Mater. Chem. Phys. 134 (2012) 26.

[9] H. Kim, S. Lee, Y. Han, J. Park, Mater. Chem. Phys. 113 (2009) 441.

[10] L. Montanaro, Y. Jorand, G. Fantozzi, A. Negro, J. Eur. Ceram. Soc. 18 (1998) 1339.

[11] F.S. Ortega, A.E.M. Paiva, J.A. Rodrigues, V.C. Pandolfelli, Cerâmica 49, 309 (2003) 1.

[12] G.D. Soraru, R. Campostrini, A.A. Ejigu, E. Zera, P. Jana, J. Ceram. Soc. Jpn. 124 (2016) 1023.

[13] H. Yue, H. Wang, J. Tian, Ceram. Int. 40 (2014) 8525.

[14] J.-H. Eom, Y.-W. Kim, S. Raju, J. Asian Ceram. Soc. 1 (2013) 220.

[15] J. Yang, J. Yu, Y. Huang, J. Eur. Ceram. Soc. 31 (2011) 2569.

[16] A.R. Studart, U.R. Gonenbach, E. Tervoort, L.J. Gauckler, J. Am. Ceram. Soc. 89 (2006) 1771.

[17] T. Fey, U. Betke, S. Rannabauer, M. Scheffler, Adv. Eng. Mater. 19 (2017) 1700369.

[18] S. Tripathy, D.S. Saini, D. Bhattacharya, J. Asian Ceram. Soc. 4 (2016) 149.

[19] M. Dressler, S. Reinsch, R. Schadrack, S. Benemann, J. Eur. Ceram. Soc. 29 (2009) 3333.

[20] R.C.O. Romano, V.C. Pandolfelli, Cerâmica 52, 322 (2006) 213.

[21] K. Schwartzwalder, A.V. Somers, "Method of making porous ceramic articles", US Patent no 3090094 (1963). 
[22] C.R. Rambo, E. Sousa, A.P.N. Oliveira, D. Hotza, P. Greil, J. Am. Ceram. Soc. 89 (2006) 3373.

[23] H. Wu, S. Qiang, Q. Fan, X. Zhao, P. Liu, P. Li, J. Liang, W. Wu, Appl. Clay Sci. 152 (2018) 295.

[24] N. Curetti, C. Bonadiman, R. Compagnoni, L. Nodari, I. Corazzari, A. Pavese, Lithos 314-315 (2018) 156.

[25] H. Sreenivasan, P. Kinnunen, E.-P. Heikkinen, M. Illikainen, Miner. Eng. 113 (2017) 47.

[26] G.O. Lepore, L. Bindi, G. Pedrazzi, S. Conticelli, P. Bonazzi, Lithos 286-287 (2017) 191.

[27] J.L. Bárcena, M. Urbina, A.P. Rowlands, P. Beneitez, A. Millán, T. Calderón, Radiat. Prot. Dosim. 84 (1999) 289.

[28] C. Balland-Bolou-Bi, B.E. Bolou-Bi, N. Vigier, C. Mustin, A. Poszwa, Chem. Geol. 506 (2019) 17.

[29] L. Xu, T. Han, J. Li, Y. Xiong, S. Guo, Compos. Sci. Technol. 145 (2017) 78.

[30] X.H. Yang, S.W. Ren, W.B. Wang, X. Liu, F.X. Xin, T.J. Lu, Compos. Sci. Technol. 118 (2015) 276.

[31] L. Lapcík, M. Vasina, B. Lapcíkova, E. Otyepkova, K.E. Waters, Compos. B Eng. 77 (2015) 304.

[32] L. Yuan, A. Han, M. Ye, X. Chen, C. Ding, L. Yao, Sol. Energy 163 (2018) 453.

[33] X.F. Lu, L.A. Majewski, A.M. Song, Org. Electron. 9
(2008) 473.

[34] R.P.S. Dutra, L.R. Araújo Pontes, Cerâmica 48, 308 (2002) 223.

[35] J.M. Bigham, T.M. Bhatti, A. Vuorinen, O.H. Tuovinen, Hydrometallurgy 59 (2001) 301.

[36] A. Camacho, J.K.W. Lee, J.D.F. Gerald, J. Zhao, Y.A. Abdu, D.M. Jenkins, F.C. Hawthorne, T.K. Kyser, R.A. Creaser, R. Armstrong, L.W. Heaman, Earth Planet. Sci. Lett. 341-344 (2012) 255.

[37] E. Schingaro, K. Kullerud, M. Lacalamita, E. Mesto, F. Scordari, D. Zozulya, M. Erambert, E.J.K. Ravna, Lithos 210-211 (2014) 1.

[38] S. Sharma, S. Komarneni, Appl. Clay Sci. 42 (2009) 553.

[39] A.C. Cabral, L.S. Cavalcante, R.C. Deus, E. Longo, A.Z. Simoes, F. Moura, Ceram. Int. 40 (2014) 4445.

[40] N. Sangiorgi, L. Aversa, R. Tatti, R. Verucchi, A. Sanson, Opt. Mater. 64 (2017) 18.

[41] A.L.B. Baccaro, I.G.R. Gutz, Quim. Nova 41 (2018) 326.

[42] A.A.S. Silva, J.A. Sampaio, A.B. Luz, S.C.A. França, C.M. Ronconi, J. Braz. Chem. Soc. 24 (2013) 1366. (Rec. 18/11/2019, Rev.06/05/2020, Ac.01/06/2020) 